Research Article

\title{
Creep Mechanics of the High-Stress Soft Rock under Grade Unloading
}

\author{
Shunjie Huang $\mathbb{D},{ }^{1,2}$ Xiangrui Meng, ${ }^{1,2}$ Guangming Zhao $\mathbb{D},{ }^{1,2}$ Yingming Li $\mathbb{D},{ }^{1,2}$ \\ Gang Liu $\mathbb{C}^{1,2,3}$ Chunliang Dong, ${ }^{1,2}$ Xiang Cheng, ${ }^{1,2,4}$ Wensong Xu $\mathbb{C}^{1,},{ }^{1,2}$ Chongyan Liu, ${ }^{1,2}$ \\ and Jun Zhou ${ }^{1,2}$ \\ ${ }^{1}$ State Key Laboratory of Mining Response and Disaster Prevention and Control in Deep Coal Mines, \\ Anhui University of Science and Technology, Huainan 232001, China \\ ${ }^{2}$ Key Laboratory of Ministry of Education for Efficient Coal Working Sponsored Jointly by Anhui Province \\ and Ministry of Education, Anhui University of Science and Technology, Huainan, Anhui 232001, China \\ ${ }^{3}$ Heilongjiang Ground Pressure \& Gas Control in Deep Mining Key Lab, Heilongjiang University of Science \& Technology, \\ Harbin 150022, China \\ ${ }^{4}$ Post-Doctoral Research Station, Huaibei Mining Corporation Limited, Huaibei 235006, China
}

Correspondence should be addressed to Guangming Zhao; guangmingzhao@163.com and Yingming Li; libo_1296@126.com

Received 4 August 2020; Revised 27 October 2020; Accepted 28 October 2020; Published 16 November 2020

Academic Editor: Fengqiang Gong

Copyright $($ C 2020 Shunjie Huang et al. This is an open access article distributed under the Creative Commons Attribution License, which permits unrestricted use, distribution, and reproduction in any medium, provided the original work is properly cited.

In order to study the creep behavior of deep soft rock, gritstone was chosen as the research subject, and a rock triaxial rheometer (Rock 600-50) and acoustic emission (AE) system (SH-II) were used to carry out the grade unloading confining pressure creep test under a high-stress level. The test results showed that the lateral creep behavior of the gritstone was more prominent than the axial creep under the initial high confining pressure. Under the same confining pressure, the creep strain rate (the direction the same as strain) of the gritstone decreases with the increase in axial pressure. As shown by the AE count, AE signals were generated throughout the entire test process, indicating that the creep was a "microdynamic" process. The creep behavior was characterized by a significant confining pressure effect. As the confining pressure was decreased, the degree of creep increases significantly. During the test, the AE energy increased on the whole but decreases during the creep phase. During the entire test process, the overall energy in the constant deviatoric stress grade unloading of the confining pressure was $45 \%$ higher than that in the constant axial pressure grade unloading. The degree of failure of the rock was different in these two unloading creep tests, and the constant axial pressure grade unloading of the confining pressure entails greater damage than the constant deviatoric stress grade unloading of the confining pressure. The main reason was that the former had a lower confining pressure level and longer creep process than the latter, and the sample was mainly characterized by creep damage and large cumulative damage, while the latter features mainly unloading damage. Through the inversion of the Burgers constitutive model and nonlinear damage constitutive model for the creep test curve, the nonlinear constitutive equation can better fit the accelerated creep stage, which suggested that this model can describe the accelerated creep characteristics of the high-stress soft rock.

\section{Introduction}

Creep is one of the important mechanical behaviors of rocks $[1,2]$. As the depth of activity in coal mines increases, the stress which rocks in the vicinity of roadways were subject to has increased significantly. In a high-stress environment, the rock mass shows certain fundamental changes such as soft rock characteristics, prominent creep behavior, and rheological properties [3-5]. The deformation and failure of the surrounding rock during roadway excavation do not happen immediately but were a long-term and continuous dynamic process as the rock tries to adjust itself to the duration and nature of the process. The rock surrounding the deep roadway was affected by the high three-dimensional ground 
stress for a long time before excavation and was characterized by slow deformation [6]. Meanwhile, the roadway excavation was, in effect, the unloading process of the rock mass, and the stress field was redistributed due to the excavation unloading; the rock mass near the excavation face was characterized by the long-term creep properties [7]. This was specifically represented by the continuous floor heave and convergence of the sides after excavation. Even if timely support was conducted after excavation, it was impossible to keep the surrounding rock from deformation for a long time [8]. Most studies on rock creep tests were based on the loading mechanics, and there were fewer studies that pertain to the unloading creep tests of the high-stress soft rock. Therefore, studies on unloading creep of the soft rock in high-stress environments were of great engineering significance for determining the deformation and failure mechanism of the soft rock roadway in a high-stress environment and for the presentation of appropriate surrounding rock reinforcement measures to maintain the stability of the roadway.

Many scholars have studied rock creep using laboratory tests and field tests based on practical engineering. The relationship between the axial strain and the lateral strain in the process of creep and unloading was obtained through the creep test under different paths [9-11]. Huang et al. [12] carried out the marble creep test during the constant axial pressure grade unloading of the confining pressure under high stress and obtained the relationship between the extent of grade unloading and the deviatoric stress at failure, elastic modulus, rupture angle, and steady-state creep time, and the test data were fitted. Wang et al. [13] conducted a rheological study of the grade unloading of the confining pressure on argillaceous siltstone under different stress levels and showed that the rock rheological process was anisotropic, with obvious axial flow deformation under high confining pressure; the lateral deformation was greater than the axial deformation under low confining pressure. The dilatancy and fracture characteristics of soft rock during creep were studied by triaxial unloading confining pressure test $[14,15]$. Yang et al. [16] carried out triaxial rheological studies on the diabase with different stress paths and concluded that there would be three stages of deceleration, constant velocity, and accelerated creep under the fracture stress level. The rheological process was mainly constant rate creep, and the transverse strain was greater than the axial strain, which was the main reason for the expansion of the rock creep process. $\mathrm{Xu}$ et al. [17] carried out a triaxial creep test on the silty mudstone under different confining pressures, revealing the influence of confining pressure on rock deformation and strength, and demonstrated that each creep parameter was positively correlated with the confining pressure and shear strength, and long-term strength of the rock tended to decrease with the increase in the confining pressure. Zhang and $\mathrm{Fu}[18]$ conducted a triaxial creep test on mudstone under different confining pressures and concluded that the attenuation creep stage increased with the increase in axial pressure and deviatoric stress with an exponential relationship between the steady-state creep and the deviatoric stress. According to the triaxial grade loading test on the mudstone in $[19,20]$, under constant axial pressure, the transient deformation and creep deformation of the mudstone decreased with the increase in the confining pressure, and the large deformation in the initial stage of creep was obvious. During the loading of the confining pressure, the relationship between the transient strain and axial stress was approximately linear. Gong et al. [21] studied the change law of the $\mathrm{AE} b$ value with the time for creep in different stages through the short-term creep test of the grade loading and unloading of the red sandstone and predicted the rock creep failure based on the change characteristics of the $b$ value. In the unloading process of rock samples, the event and energy of $\mathrm{AE}$ had different trends in different stages of unloading creep [22-25]. Wu et al. [26] carried out the loading creep and $\mathrm{AE}$ test on the rock salt and concluded that the $\mathrm{AE}$ characteristic parameters were directly proportional to the creep rate, and the cumulative change curve of AE had the same trend as the strain curve in the creep process. The authors further used AE to predict the internal failure of the rock salt. Through the AE-based triaxial creep test on the salt rock, Liu et al. [27] concluded that the AE signals were characterized by three stages of increase-decrease-increase, and the AE signal was ahead of the creep strain curve, which could reflect the development trend of the strain. Jiang et al. [28] obtained the AE signal morphology of the creep process through the statistics of the AE signal law in the creep test process of the sandstone. Wang et al. [29] obtained the evolution law of AE energy in different creep stages through the creep AE test on the fractured rock. When the rock was damaged, the AE signal would increase significantly, and the AE energy reached a higher value when the sample was damaged. In the triaxial unloading creep test, the accelerated creep deformation in the final stage of confining pressure and the corresponding parameters of the triaxial creep constitutive model were obtained by parameter identification of optimization algorithm [30]. Zhang et al. [31] concluded that, through the unloading rheological experiment of hard rock, the characteristics of deformation in the creep process were obtained, and a fractional-order nonlinear creep constitutive model was proposed. At present, there were a few studies on the AE characteristics during the rock creep process, especially on AE during the long-term grade unloading creep.

In this paper, gritstone was taken as the research object, and the plots of the constant axial pressure grade unloading and constant deviatoric stress grade unloading of the confining pressure, combined with the AE system, were adopted to conduct the indoor grade unloading creep test on the high-stress soft rock. The characteristics of the creep deformation, unloading transient deformation under different unloading paths, and the relationship between the AE count and the energy in the test were studied. Then, the parameters of the Burgers creep model and the nonlinear model were inversed for the test data to determine the appropriate constitutive equation, and the relationship between the model parameters and the stress level was obtained. The results can provide an important theoretical basis for the creep deformation and stability evaluation of the rocks surrounding high-stress roadways (tunnel) in underground 
engineering and enrich theoretical studies on the unloading creep mechanics of the deep soft rock.

\section{Materials and Methods}

2.1. Sample Preparation. Gritstone was used as the test material in this study. Based on the International Society for Rock Mechanics (WASRM) test protocol, the rock sample was made into a cylinder of diameter $50 \mathrm{~mm}$ and height $100 \mathrm{~mm}$. The two ends of the processed sample were as flat as possible, and the roughness was $\leq 0.02 \mathrm{~mm}$. It was dried naturally. Ultrasonic testing was carried out on the sample using an acoustic wave tester. The detected $S$-wave velocity was $1992-2016 \mathrm{~m} / \mathrm{s}$, and the average wave velocity was $2004 \mathrm{~m} / \mathrm{s}$; the $P$ wave velocity was $2688-2746 \mathrm{~m} / \mathrm{s}$, and the average wave velocity was $2717 \mathrm{~m} / \mathrm{s}$. The standard sample is shown in Figure 1, and the acoustic detection test is shown in Figure 2.

2.2. Test Equipment. The rock triaxial rheometer (Rock 60050), made in France, and the AE monitoring system (sensor highway II) were used in the test, as shown in Figure 3. The rheometer consists of the axial pressure loading system, confining pressure loading system, ENERPAC hydraulic hand pump, intelligent control system, and data acquisition system. A maximum axial deviatoric stress of $375 \mathrm{MPa}$ and confining pressure of $60 \mathrm{MPa}$ can be applied. The Sensor Highway II system, jointly developed by PAC and EPRI of the United States, was provided with high sensitivity sensors and integrated amplifier/sensor AE probe; the detection sensitivity of partial discharge can reach $50 \mathrm{pC}$. The sensor was fixed outside the instrument. One AE transducer was used during the graded unloading creep test. The trigger threshold of $\mathrm{AE}$ was set to $40 \mathrm{~dB}$ for each test, and fullwaveform data were recorded with a sampling rate of 1 MSPS. The pretrigger time was $1.024 \mathrm{~ms}$ [32].

2.3. Test Scheme. In this test, two test paths, i.e., constant axial pressure grade unloading and constant deviatoric stress grade unloading of the confining pressure, were used to carry out the grade unloading creep test. The initial confining pressure of the unloading creep was set at $30 \mathrm{MPa}$ (according to the actual engineering situation, the cooling chamber of a $-980 \mathrm{~m}$ shaft bottom of a certain mine was taken as the engineering background, and the original ground stress of the surrounding rock chamber was $p_{0}=30.4 \mathrm{MPa}$ ); the axial pressure value was $70 \%$ of the conventional triaxial strength. According to the triaxial compression test of the gritstone sample, $R c=130.85 \mathrm{MPa}$ when $\sigma_{3}=30 \mathrm{MPa}$, and the axial pressure was set to $91 \mathrm{MPa}$. The curve of the triaxial compression test is shown in Figure 4. The test process was divided into three stages: (1) according to the hydrostatic pressure condition, $\sigma_{1}=\sigma_{3}=30 \mathrm{MPa}$ was applied at the loading rate of $0.05 \mathrm{MPa} / \mathrm{s}[33,34]$. (2) After $\sigma_{1}$ and $\sigma_{3}$ were stable, $\sigma_{3}=30 \mathrm{MPa}$ was kept constant. $\sigma_{1}$ was applied to the preset value at the loading rate of $0.05 \mathrm{MPa} / \mathrm{s}$, and the $\mathrm{AE}$ monitoring system was turned on synchronously. (3) The creep time was set to be $12 \mathrm{~h} /$ grade, the unloading level of the

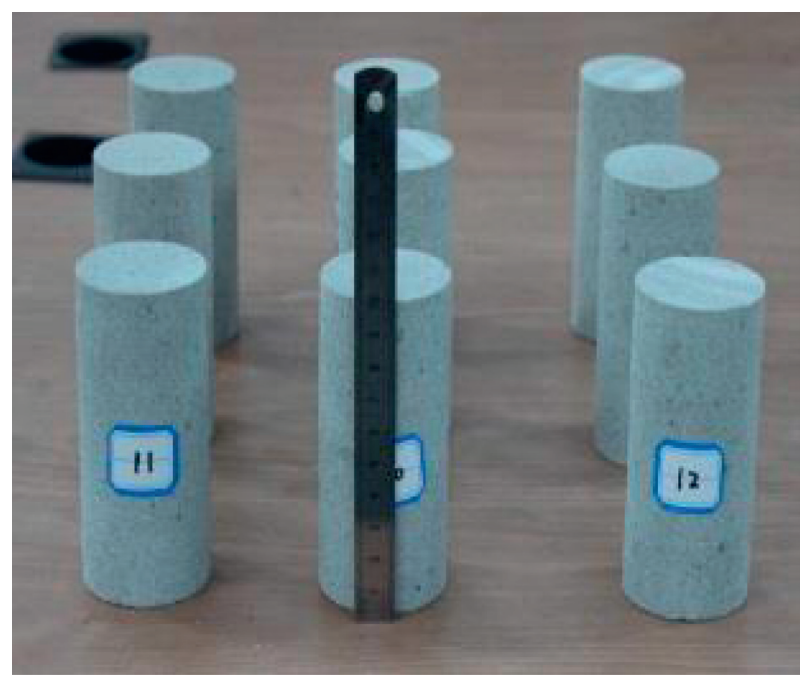

FIGURE 1: Standard gritstone samples.

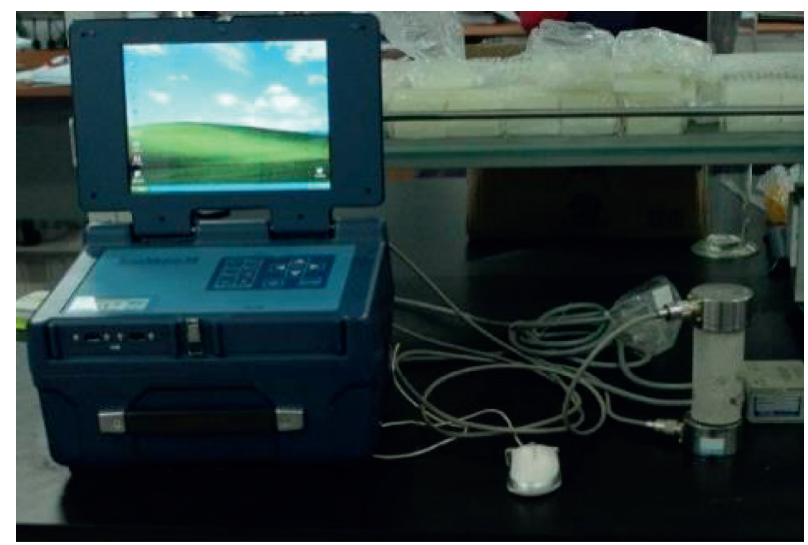

Figure 2: Wave velocity testing equipment.

confining pressure was $4 \mathrm{MPa} /$ grade, and the unloading rate was $0.05 \mathrm{MPa} / \mathrm{s}$. Scheme 1: keep $\sigma_{1}$ constant until the sample was damaged. Scheme 2: keep the deviatoric stress constant ( $\sigma_{1}-\sigma_{3}$ unchanged), and increase $\sigma_{1}$ by the same amount when $\sigma_{3}$ was unloaded (after the end of each stage of creep, the confining pressure was unloaded $4 \mathrm{MPa}$, and the unloading rate was at $0.05 \mathrm{MPa} / \mathrm{s}$; meanwhile, the axial pressure also unloaded $4 \mathrm{MPa}$ at the unloading rate at $0.05 \mathrm{MPa} / \mathrm{s}$. Therefore, the deviatoric stress remained constant), until the sample was damaged. The stress paths used in this test are shown in Tables 1 and 2.

\section{Results and Discussion}

3.1. Creep Test Curve. The strain-time curves under the two test schemes were obtained by the designed grade unloading creep test scheme, as shown in Figures 5 and 6 . The strain was positive in the case of deformation by compression and negative in case of deformation by outward expansion. As shown by the experimental results, the lateral creep behavior was more prominent than the axial creep behavior. Therefore, this paper focuses on the study of lateral strain. The grade creep variables 


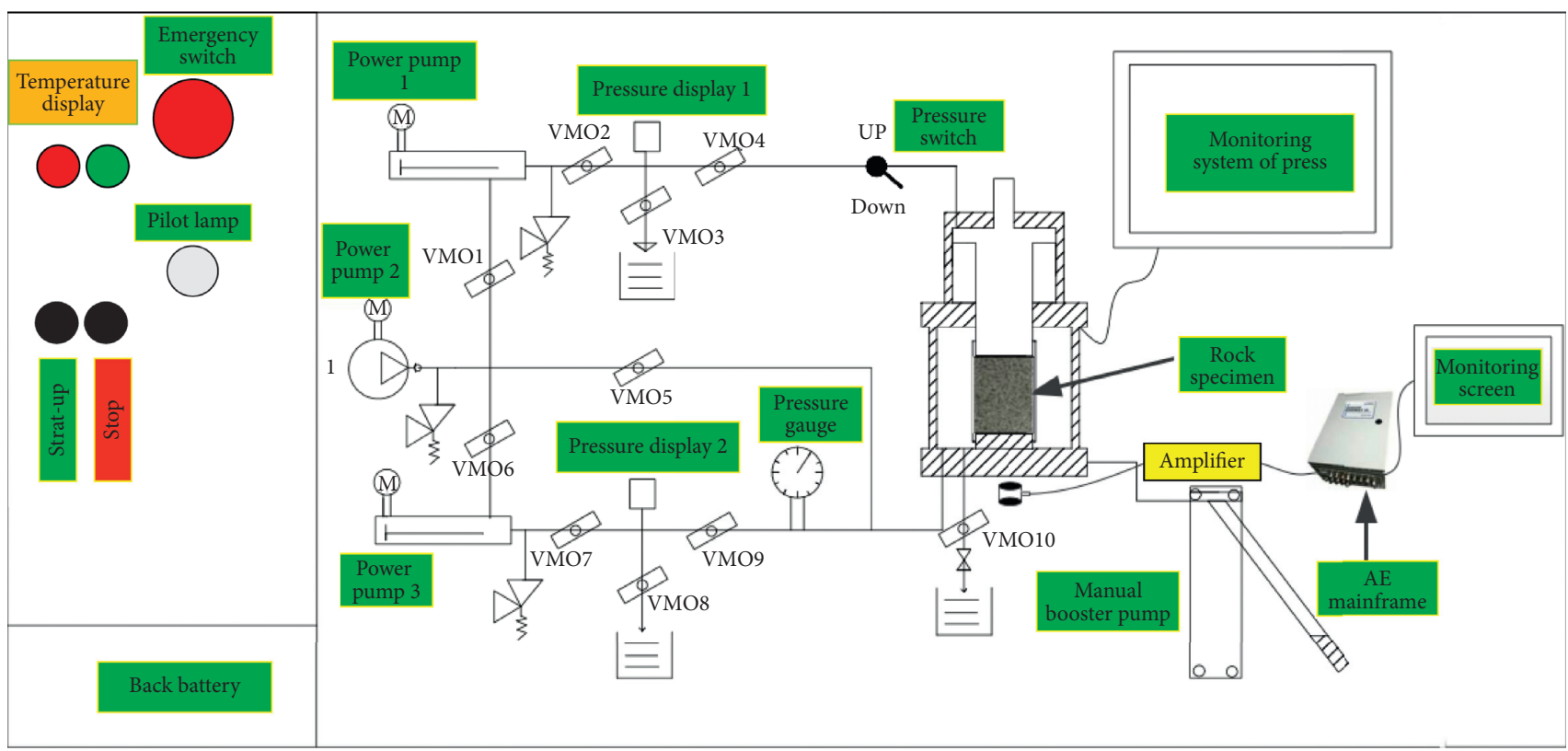

Figure 3: Test equipment.

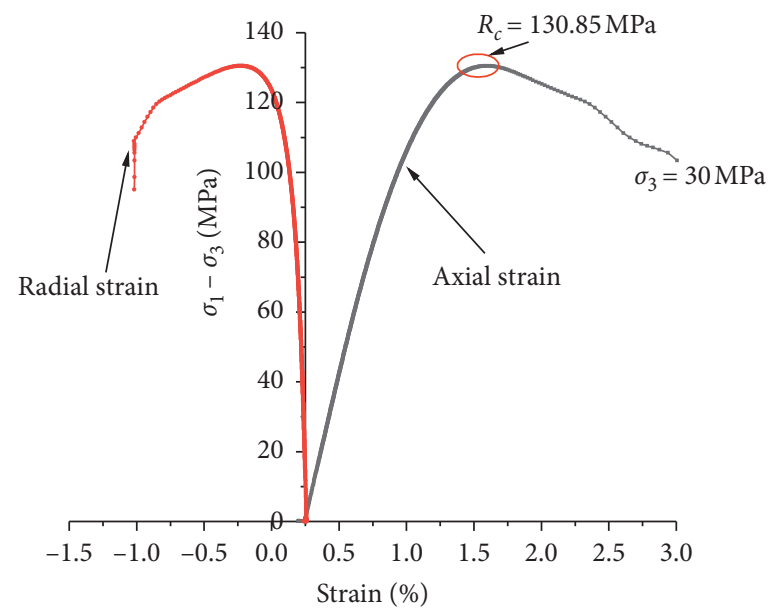

FIGURE 4: Gritstone triaxial compression test.

TABLE 1: Stress path of unloading confining pressure with constant $\sigma_{1}$.

\begin{tabular}{lcccc}
\hline Unloading & $\sigma_{1}(\mathrm{MPa})$ & $\sigma_{3}(\mathrm{MPa})$ & $\left(\sigma_{1}-\sigma_{3}\right)(\mathrm{MPa})$ & Unloading rate $(\mathrm{MPa} / \mathrm{s})$ \\
\hline First stage & 130.85 & 30 & 100.85 & 0.05 \\
Second stage & 130.85 & 26 & 104.85 & 0.05 \\
Third stage & 130.85 & 22 & 108.85 & 0.05 \\
Fourth stage & 130.85 & 18 & 112.85 & 0.05 \\
Stage $n$ & 130.85 & $30-4 *(n-1)$ & $100.85-4 *(n-1)$ & 0.05 \\
\hline
\end{tabular}

Note. $n$ shows how many grades are in the creep stage.

and the unloading transient strain data of these two unloading paths are shown in Table 3.

\subsubsection{Constant Axial Pressure Grade Unloading of Confining} Pressure. Figure 7 shows the creep curve of the grade unloading of the gritstone sample at constant $\sigma_{1}=91 \mathrm{MPa}$ and an initial confining pressure of $\sigma_{3}=30 \mathrm{MPa}$. During the early stages of the test, $\sigma_{3}=30 \mathrm{MPa}$, and the creep value of the sample was $7.02 \times 10^{-4}$ within 12 hours, accounting for $18.32 \%$ of the total strain. During the creep process of $\sigma_{3}=26 \mathrm{MPa}$, the creep was steady, and the creep value was $3.12 \times 10^{-4}$, accounting for $8.15 \%$ of the total strain; at the confining pressure levels of $22 \mathrm{MPa}, 18 \mathrm{MPa}$, and $14 \mathrm{MPa}$, the creep deformation was very small, and the creep value was $1.05 \times 10^{-4}, 1.12 \times 10^{-4}$, and $1.42 \times 10^{-4}$, accounting for 
TABLE 2: Stress path of unloading confining pressure with constant $\sigma_{1}-\sigma_{3}$.

\begin{tabular}{lcccc}
\hline Unloading & $\sigma_{1}(\mathrm{MPa})$ & $\sigma_{3}(\mathrm{MPa})$ & $\left(\sigma_{1}-\sigma_{3}\right)(\mathrm{MPa})$ & Unloading rate $(\mathrm{MPa} / \mathrm{s})$ \\
\hline First stage & 130.85 & 30 & 100.85 & 0.05 \\
Second stage & 126.85 & 26 & 100.85 & 0.05 \\
Third stage & 122.85 & 22 & 100.85 & 0.05 \\
Fourth stage & 118.85 & 18 & 100.85 & 0.05 \\
Stage $n$ & $\sigma_{1}-4 *(n-1)$ & $30-4 *(n-1)$ & 100.85 & 0.05 \\
\hline
\end{tabular}

Note. $n$ shows how many grades are in the creep stage.

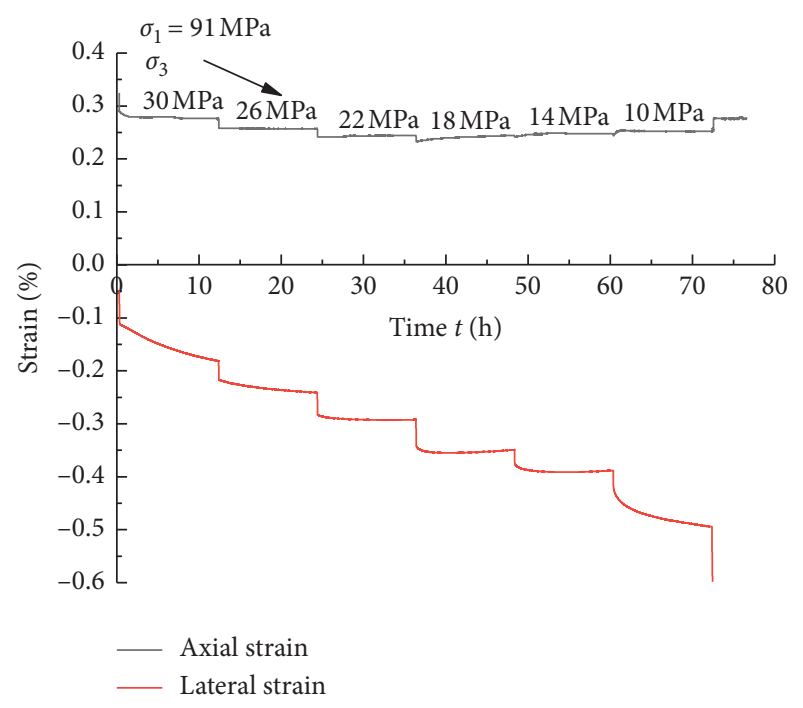

FIGURE 5: Creep curve of constant axial pressure grade unloading of confining pressure.

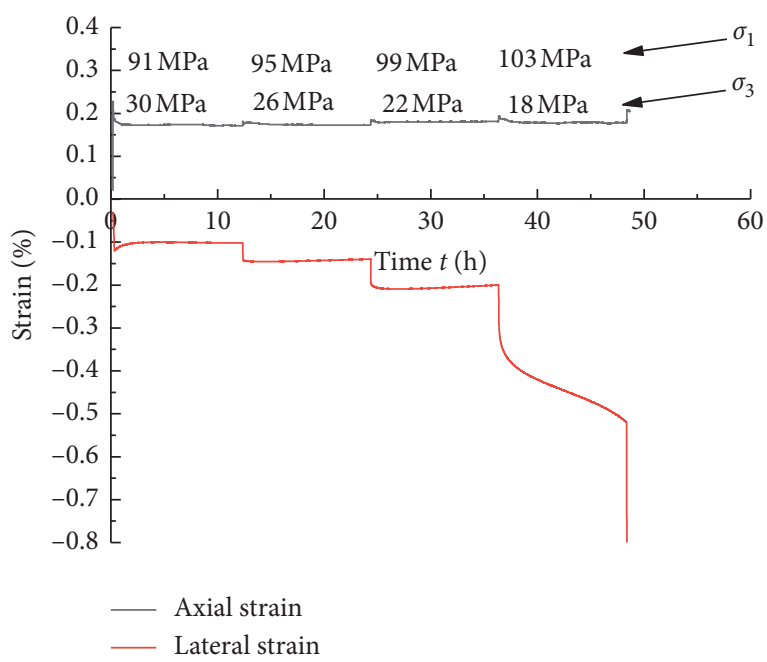

Figure 6: Creep curve of constant deviatoric stress grade unloading of confining pressure.

$2.74 \%, 2.92 \%$, and $3.71 \%$ of the total strain, respectively. The creep deformation in these three stages was small, and the sample was in the elastic stage with good integrity. At the creep stage of $\sigma_{3}=10 \mathrm{MPa}$, the creep deformation increases obviously, and the creep deformation was $7.69 \times 10^{-4}$, accounting for $20.08 \%$ of the total strain, with the lateral deformation being different from the previous stages. At this time, since the sample experiences the initial high-stress environment and the unloading process of the confining pressure, the rock undergoes serious internal damage, the internal bearing capacity of the sample weakens with time, and the sample still retains the bearing capacity partially. In the next grade of confining pressure unloading, the bearing capacity of the gritstone was not enough to resist the increase in axial compression, and the cracks in the sample expand rapidly and form a through fracture surface, which finally shows the failure of the sample.

3.1.2. Constant Deviatoric Stress Grade Unloading of Confining Pressure. As shown in Figure 7, at the creep stage of $\sigma_{3}=30 \mathrm{MPa}$, the value of creep was $1.61 \times 10^{-4}$, accounting for $2.89 \%$ of the total strain. This was the rheological hardening stage that shows a nonlinear hardening phenomenon. At the stress condition of $\sigma_{3}=26 \mathrm{MPa}$ and $\sigma_{3}=22 \mathrm{MPa}$, the creep behavior was represented by stable creep, and the grade creep deformation was $1.4 \times 10^{-5}$ and $1.15 \times 10^{-4}$, accounting for $0.25 \%$ and $2.07 \%$ of the total strain, respectively. The creep deformation was so small that the sample can be considered to be in the elastic stage and relatively stable. At $\sigma_{3}=18 \mathrm{MPa}$, the creep was unstable, and the initial creep stage was decelerated creep, followed by the uniform creep stage and finally the accelerated creep stage. At this stage, the creep value reaches the maximum, which was $2.226 \times 10^{-3}$, accounting for $40.02 \%$ of the total strain. Then, the sample was seriously damaged, but no creep failure of the sample occurs.

Figure 7 shows the curves of transient unloading strain and variation in creep strain with the confining pressure unloading under two unloading paths. As shown by the curves, under the initial high-stress level, the transient unloading strain deformation changes greatly with the transient unloading of the confining pressure, the strain was $1.110 \times 10^{-3}$ and $1.180 \times 10^{-3}$, respectively, under the two schemes, and the deformation first decreases and then increases with the decrease in the confining pressure. The main reason was that the initial fissures in the sample were compressed under the initial high confining pressure, and "transient rebound" occurs with the unloading of the confining pressure. When the confining pressure was unloaded to a certain extent, the sample enters the elastic stage. At this time, the sample was relatively stable internally. During the transient unloading process, the sample was still in the high confining stress environment, and so, the deformation was small. When the confining pressure was reduced to a certain extent, new cracks appear in the sample, 
TABLE 3: Lateral strain values under two test schemes.

\begin{tabular}{|c|c|c|c|c|}
\hline \multirow{2}{*}{ Sample } & \multirow{2}{*}{$\sigma_{1}(\mathrm{MPa})$} & \multirow{2}{*}{$\sigma_{3}(\mathrm{MPa})$} & \multicolumn{2}{|c|}{ Lateral strain $\left(10^{-6}\right)$} \\
\hline & & & Instantaneous strain & Creep in each stage \\
\hline \multirow{6}{*}{ XH-b301 } & \multirow{6}{*}{91} & 30 & 1110 & 702 \\
\hline & & 26 & 3599 & 312 \\
\hline & & 22 & 334 & 105 \\
\hline & & 18 & 454 & 112 \\
\hline & & 14 & 246 & 142 \\
\hline & & 10 & 297 & 769 \\
\hline \multirow{4}{*}{ XH-b303 } & 91 & 30 & 1180 & 161 \\
\hline & 95 & 26 & 390 & 14 \\
\hline & 99 & 22 & 488 & 115 \\
\hline & 103 & 18 & 987 & 2226 \\
\hline
\end{tabular}

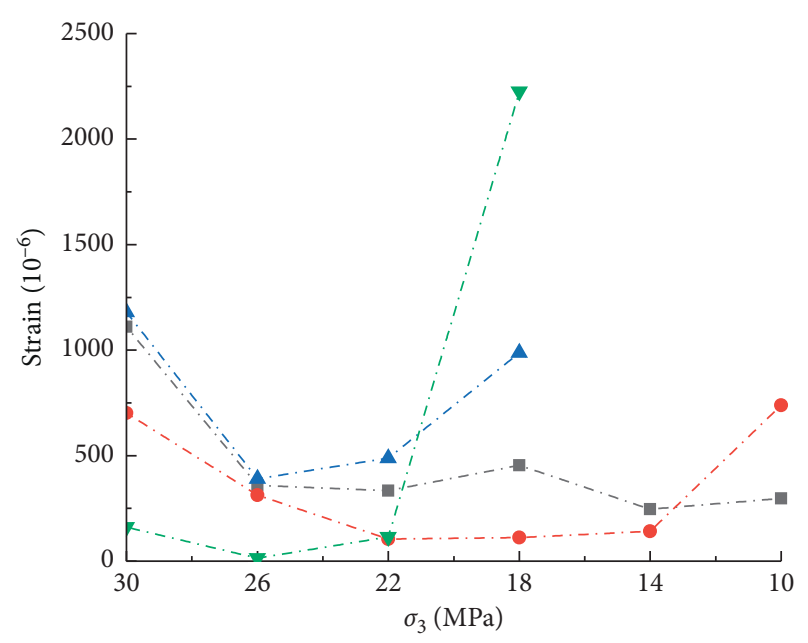

- - First scheme instant unload

- - First scheme within each level

$\rightarrow$ - Second scheme instant unload

$\rightarrow$ - Second scheme within each level

FIgURE 7: Relationship between strain and confining pressure under two schemes.

which develop and expand with time, and the transient unloading tends to increase. This indicates that creep depends not only on the time but also on the stress level. Creep deformation and transient unloading deformation have similar laws; that is, both were large in the initial stage, small in the intermediate process, and large in the final stage. Both reveal that the deformation was small in the elastic stage and large in the damage stage.

3.2. AE Characteristics during Creep Test. Figures 8 and 9 show the strain-time-AE count curves when these two schemes were tested. When gritstone was deformed, its internal defects will cause damage under the action of the external force. During damage and failure, part of the energy was released in the form of an elastic wave and propagates rapidly in the rock material, resulting in AE phenomenon. $\mathrm{AE}$ count was the number of ringing pulses in a test when the $\mathrm{AE}$ signal exceeds the threshold. The AE count value was relatively large in the initial creep stage. In this process,

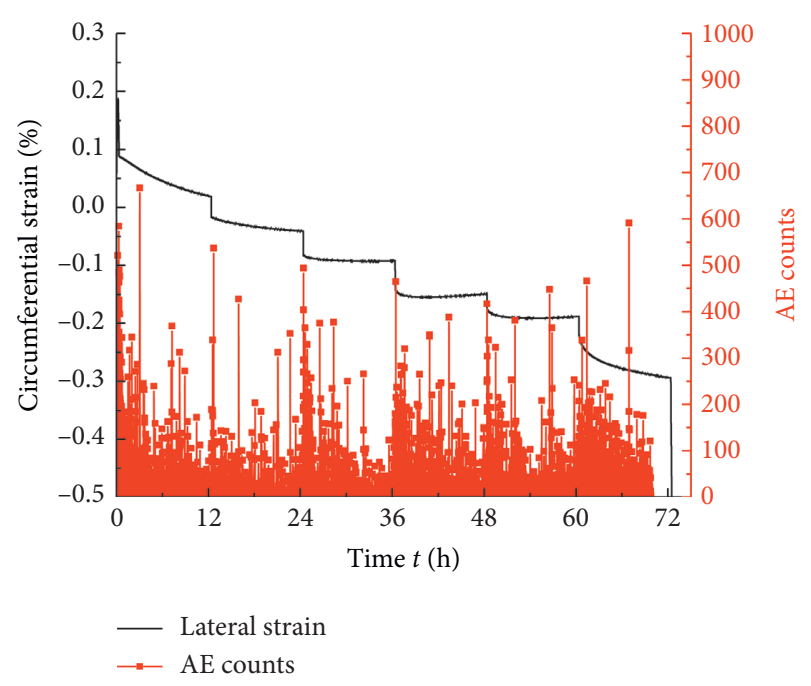

FIGURE 8: Lateral strain-time-AE count curve of constant axial pressure grade unloading confining pressure.

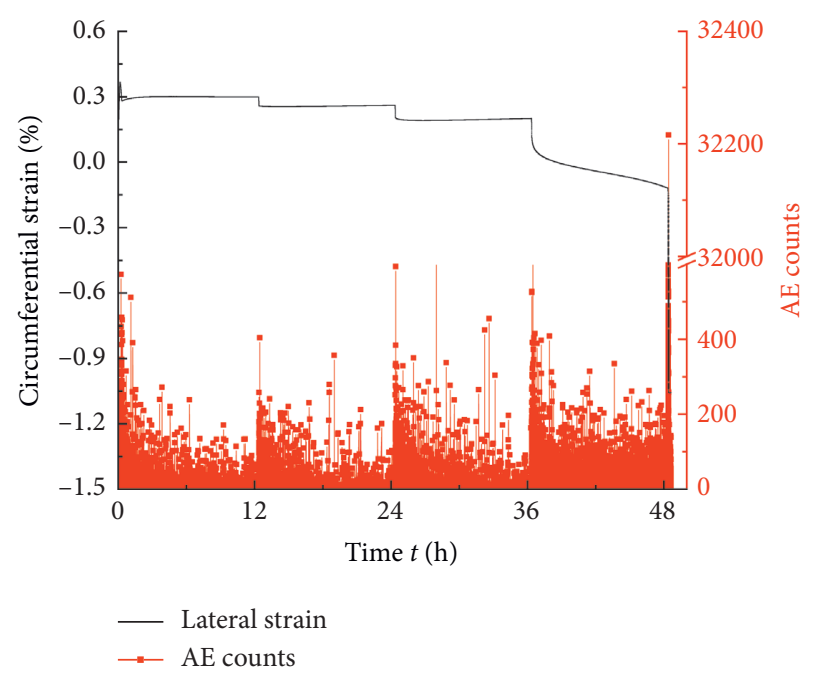

FIGURE 9: Lateral strain-time-AE count curve of constant deviatoric stress grade unloading confining pressure.

transient application of the confining pressure and the axial pressure causes damage to the microelements in the gritstone and the closure of microcracks under the action of the 
confining pressure. So, the AE signal was strong in the initial stage of creep. In each grade of the creep process, with the increase in time, the bearing capacity provided by the strong crystal unit decreases, which was represented by the decrease in the AE count with time. Under the two unloading paths, the $\mathrm{AE}$ activity of the sample was strong at the initial stage of creep, and it decreases with the progression of creep. However, in the process of grade unloading, the AE signal of each grade shows a decreasing trend from strong to weak. As the axial pressure and confining pressure were constant at this time, the cracks were inhibited from being damaged continuously, and the confining pressure does work on the internal pores and cracks of the sample. At the instant of unloading of the confining pressure, the stress environment of the gritstone changes suddenly, and the cracks in the sample expand rapidly. However, the small amount of unloading does not cause sample failure but increases the degree of damage of the sample. The law of evolution of the $\mathrm{AE}$ count under the two unloading paths shows the change of the internal structure of the gritstone sample during the process from the original state to the macroscopic failure, and the compaction and degree of expansion of the internal cracks can be reflected by the evolution trend of the $\mathrm{AE}$ counts.

3.3. Characteristics of AE Energy during Creep Experiment. $\mathrm{AE}$ energy was represented by the area enclosed by the envelope line under the detection signal waveform and not the specific energy value actually released by the AE device $[35,36]$. Based on relevant research, energy accumulation was the basic parameter that can indicate rock fracture in the test process [37]. By processing the test data, the AE energystrain-time-cumulative $\mathrm{AE}$ energy curve was drawn, as shown in Figure 10.

According to Figure 10, the cumulative AE energy in the entire process can be divided into four main stages: the transient increase stage, attenuation stage, stable stage, and secondary growth stage.

(1) The transient increase stage was mainly associated with the initial loading stage and the unloading process of each grade of confining pressure of the sample; the first stage features the compaction of microcracks, and the second stage shows the formation of new cracks. As the creep proceeds, the $\mathrm{AE}$ energy increases during each grade of the confining pressure unloading, which indicates that creep has a cumulative damage effect on the rock.

(2) The attenuation stage mainly occurs in each grade of creep. In the initial unloading stage, a large amount of elastic energy of the rock sample was released. When the confining pressure of each stage was unloaded, the rock sample enters the creep stage, and the axial pressure and confining pressure maintain a relatively constant state. At this time, only the creep causes AE energy change, and only relatively weak energy was released in the creep process.
(3) The stable stage occurs within the grade during the later stages of creep. At this time, the new and old cracks maintain relative equilibrium, and the $\mathrm{cu}$ mulative AE energy does not increase. Other stages, except the final stage, may be described using similar laws.

(4) The secondary growth stage mainly occurs in the last grade of creep, as the rock sample was subjected to an initial high-stress environment, and then undergoes multiple grades of unloading, resulting in the accumulation of internal damage. The second scheme was more obvious than the first scheme, mainly because the same amount of axial pressure was incremented during the unloading of confining pressure in each grade. Therefore, the rock in scheme 2 was in a higher stress environment, showing that the slope of the cumulative AE energy increases gradually in the later stage, and the energy accumulation was positively correlated with the internal structure failure of the rock.

In the initial high-stress environment, a large amount of energy was cumulative in the rock. However, under the high confining pressure, the energy in the rock cannot be released before the main fracture, and the creep process was relatively stable. Part of the energy was released during the grade unloading, and this was slow during the creep. This was mainly manifested by the persistence of $\mathrm{AE}$ energy and the increase of cumulative AE energy, which was more significant with confining pressure unloading. In conclusion, the generation of $\mathrm{AE}$ parameters was characterized by the obvious confining pressure effect in the creep process of the gritstone under the conventional triaxial grade unloading.

Figure 11 shows the fitting curve between the cumulative $\mathrm{AE}$ energy and confining pressure after confining pressure unloading. As shown in the figure, in the initial creep stage, the rock was in the high confining stress environment, the energy was cumulative in the rock, AE was not active, energy release caused by the creep process was also small, confining pressure was reduced, the energy inside the rock was released, and the crack was expanded. The smaller the confining pressure, the greater the energy release. Moreover, with the unloading of the confining pressure, the cumulative $\mathrm{AE}$ energy increases significantly. In the first grade of creep, the sample under the two test paths was in the same stress environment, and the AE energy accumulation has little difference; in the second grade of creep, due to the supplement of axial pressure in scheme 2 compared to scheme 1 , the internal damage of the rock was intensified, the cumulative AE energy shows rapid growth, and the slope of energy accumulation increases with the decrease in the confining pressure until the rock failure occurs. In scheme 1, the AE energy accumulation and confining pressure have a linear relationship, while the relationship was cubic in scheme 2. The curve fitting of the linear function and the cubic function for test data under the two schemes was good. The correlation coefficients $R^{2}=0.9954$ in the fitting curve of scheme 1 and $R^{2}=0.9929$ in the fitting curve of scheme 2 . The high confining pressure has a binding effect on the rock, 


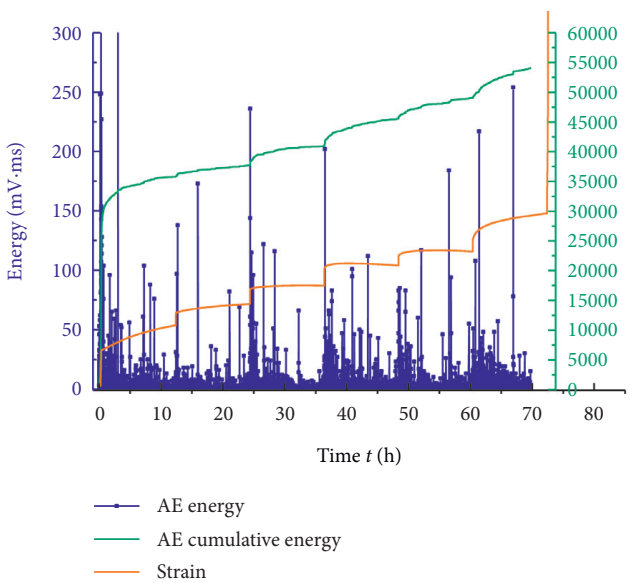

(a)

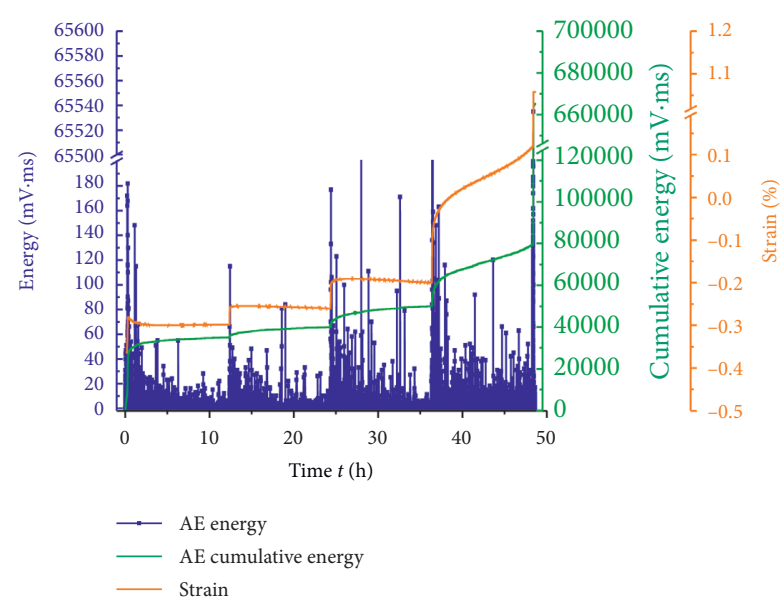

(b)

FIgure 10: Time-AE energy-cumulative AE energy-strain curve. (a) Scheme 1. (b) Scheme 2.

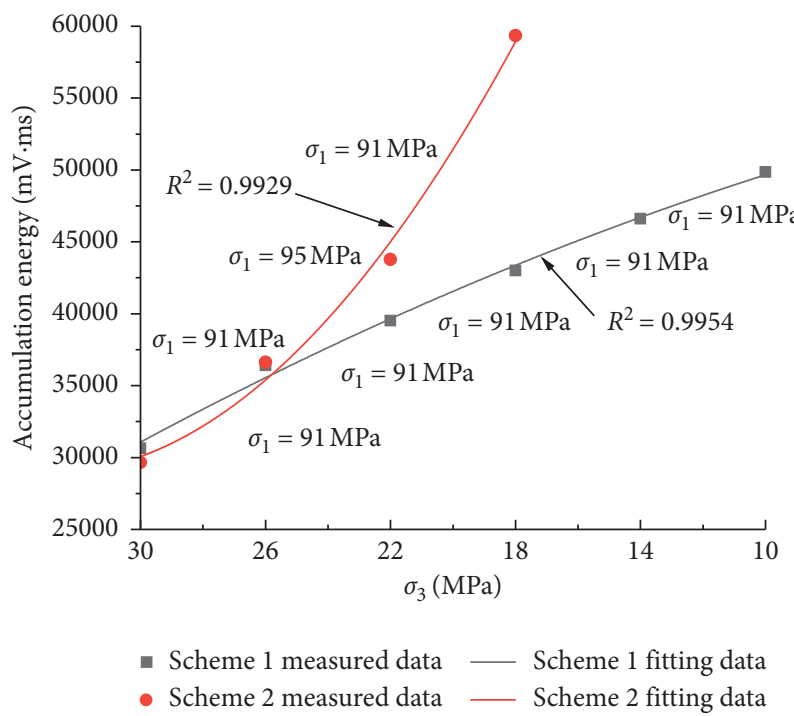

FIGURE 11: Fitting curve of cumulative AE energy and confining pressure.

which was manifested by the higher internal energy of the rock and smaller energy release during creep, and this was the main reason for the smaller energy accumulation in the first grade of creep. In the second grade and after the unloading of the confining pressure, the axial pressure of scheme 2 was greater than that of scheme 1, which accelerated the rock damage and failure. The energy release increases, and the energy accumulation increases during each grade with time. In conclusion, the change law of $\mathrm{AE}$ parameters during the grade unloading creep of the highstress soft rock showed that the grade unloading creep was characterized by a significant axial pressure effect.

3.4. Failure Pattern Analysis of the Sample in Creep Test. Figure 12 shows the failure patterns of the gritstone during the grade unloading confining pressure creep test under two schemes. From the macroscopic view, the gritstone sample shows the failure pattern of the double slope shear, the sample failed into three parts, and two large failure surfaces were formed. A relevant study showed that these two fracture surfaces were not formed synchronously. Careful observation indicates that there were fewer microcracks in the failure sample, and the other parts of the failure sample were basically intact except for the main crack and fracture surface. During the fracture process, the internal crack propagates and extends under the joint action of tensile deformation and wedge splitting force and was sheared at the moment of grade unloading of the confining pressure, which shows the joint action of the splitting failure and the slant shear failure. In Figure 12(b), a main failure surface appears, and the failure was less intense than the former, which was mainly because the confining pressure during the failure was larger than the former, and the confining pressure can restrain the intensification of sample failure. The failure mode of the sample was mainly slant shear failure, and microcracks appear in the sample failure, showing the ductile failure. The comparison of these two showed that the rupture angle obtained from the test of constant axial pressure grade unloading of the confining pressure was approximately $60^{\circ}$ and that of the constant deviator stress grade unloading of the confining pressure was $58^{\circ}$. The creep process was the damage development process of the rock. With the grade unloading of the confining pressure, the stress environment of the sample gradually decreases. The accumulation of damage in the creep process was released at the instant of unloading, which accelerates the generation of cracks in the sample, and the failure will be further deepened. Under the same confining pressure, the axial pressure in scheme 2 was greater than that in scheme 1 , that is, the stress environment of the latter was more intense than that of the former, the compressive strength between grains was reduced, the crack development and formation of failure surface were accelerated, the failure angle was reduced when the failure was finally caused, and the failure pattern was simpler than scheme 1 . 


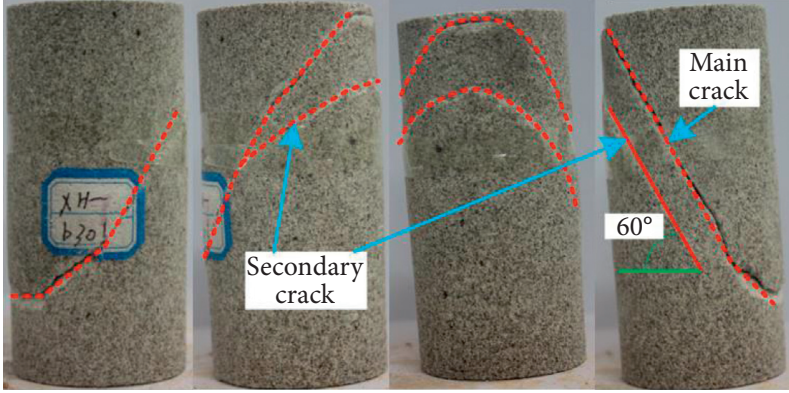

(a)

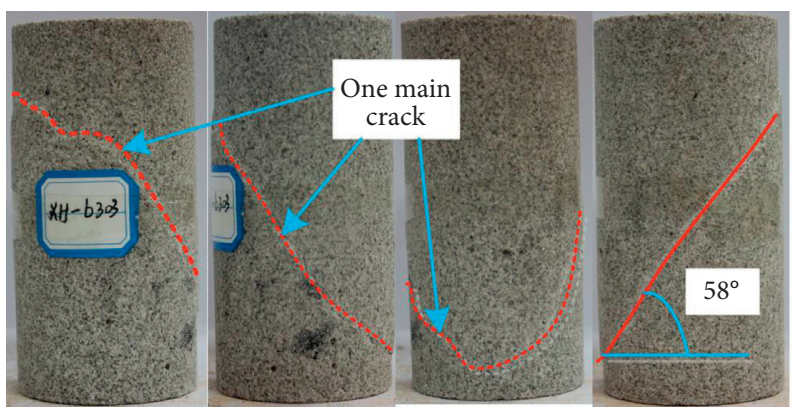

(b)

Figure 12: Failure pattern of the sample. (a) Scheme 1. (b) Scheme 2.

\section{Nonlinear Creep Model and Parameter Identification}

4.1. Establishment of the Rheological Model. According to the grade unloading creep curve and the data in Table 1, the creep deformation under the two schemes showed different characteristics in the creep process of the grade before the fracture stress level. Therefore, the creep constitutive equation of the first grade before the fracture stress level was studied. Based on the test data, the strain during the creep and creep rate versus time curve at each time were calculated. Figure 13(a) shows the relationship between the lateral creep rate and the time under the stress level of $\sigma_{1}=91 \mathrm{MPa}$ and $\sigma_{3}=10 \mathrm{MPa}$, and Figure 13(b) shows the relationship between the lateral creep rate and time under $\sigma_{1}=103 \mathrm{MPa}$ and $\sigma_{3}=18 \mathrm{MPa}$.

As shown in Figure 13, during the creep process of the grade before the fracture stress level under the two test paths, the process showed attenuation creep in the initial stage and stable and uniform creep in the intermediate stage; in the later stage, different creep behaviors were shown, with stable and uniform creep in the later stage in scheme 1 and accelerated creep in scheme 2. Although the Burgers model can fit the decelerated creep and stable uniform creep process during the creep, it cannot describe the strain characteristics in the later nonlinear accelerated rheological process. Wang et al. [13] established a new nonlinear constitutive equation through the Burgers model in series with damage bodies to describe the nonlinear accelerated creep process. The model diagram is shown in Figure 14.

When only parts I and II of the model were applicable, the model was a classical Burgers creep model, and the corresponding equation was as follows:

$$
\left\{\begin{array}{l}
\sigma_{m}=E_{m} \cdot \varepsilon_{m 1}, \\
\sigma_{m}=\eta_{m} \cdot \dot{\varepsilon}_{m 2}, \\
\sigma_{k}=E_{k} \varepsilon_{2}+\eta_{k} \dot{\varepsilon}_{2}, \\
\sigma=\sigma_{1}-\sigma_{3}=\sigma_{m}=\sigma_{K}, \\
\varepsilon=\varepsilon_{m 1}+\varepsilon_{m 2}+\varepsilon_{2},
\end{array}\right.
$$

where $\sigma_{m}$ and $\sigma_{k}$ are the stress value of parts I and II, $\varepsilon_{m 1}$ and $\dot{\varepsilon}_{m 2}$ denote, respectively, the strain of elastic elements and viscous components, and $\varepsilon_{m 2}$ represents the strain of the viscous element in part II.
The following equation can be obtained by the Laplace transform and inverse transform:

$$
\varepsilon=\left[\frac{1}{E_{m}}+\frac{t}{\eta_{m}}+\frac{1}{E_{k}} 1-e^{-\left(E_{k} / \eta_{k}\right) t}\right]\left(\sigma_{1}-\sigma_{3}\right) .
$$

When both the nonlinear damage model and the damage factor $D$ were applicable, the equation becomes

$$
\left\{\begin{array}{l}
\sigma_{m}=E_{m} \cdot \varepsilon_{m 1}, \\
\sigma_{m}=\eta_{m} \cdot \dot{\varepsilon}_{m 2}, \\
\sigma_{k}=E_{k} \varepsilon_{2}+\eta_{k} \dot{\varepsilon}_{2}, \\
\varepsilon_{D}=\frac{\sigma_{D}-\sigma_{s}}{(1-D) \eta_{D}}=\left(\frac{\sigma_{D}-\sigma_{s}}{\eta_{D}}\right) e^{\left(t-t_{1}\right)^{k}} \cdot t, \\
\sigma=\sigma_{1}-\sigma_{3}=\sigma_{m}=\sigma_{K}=\sigma_{D}, \\
\varepsilon=\varepsilon_{m 1}+\varepsilon_{m 2}+\varepsilon_{2}+\varepsilon_{D} .
\end{array}\right.
$$

The following equation can be obtained by the Laplace transform and inverse transform of the above equation:

$$
\varepsilon=\left[\frac{1}{E_{m}}+\frac{t}{\eta_{m}}+\frac{1}{E_{k}} 1-e^{-\left(E_{k} / \eta_{k}\right) t}\right] \sigma_{1}-\sigma_{3}+\frac{\sigma_{D}-\sigma_{s}}{\eta_{D}} \cdot e^{\left(t-t_{1}\right)^{k}} \cdot t .
$$

In the above constitutive equation, " $m$," " $K$," and " $D$," respectively, are the Maxwell model and Kelvin model and mechanical components corresponding to the nonlinear damage model, $E_{m}, \eta_{m}, E_{k}$, and $\eta_{k}$ are the elastic modulus and viscosity coefficient of the Maxwell model and Kelvin model, $\sigma_{D}$ is the stress of part III, and $k$ reflects the size of the creep rate of the reaction sample in the nonlinear acceleration stage.

4.2. Parameter Identification in the Nonlinear Creep Model. To verify the nonlinear rheological creep model, a nonlinear unloading creep model was used to verify the lateral creep test curve of the grade before the fracture of 


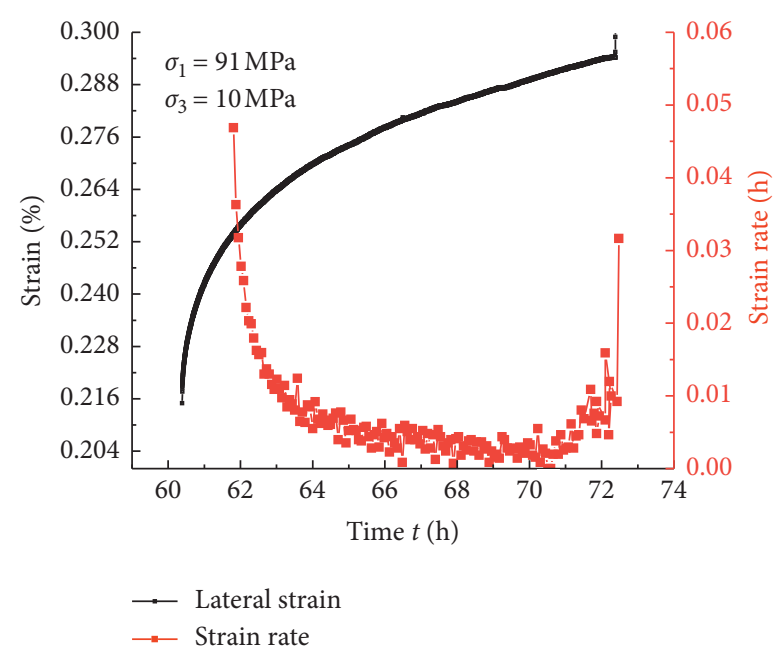

(a)

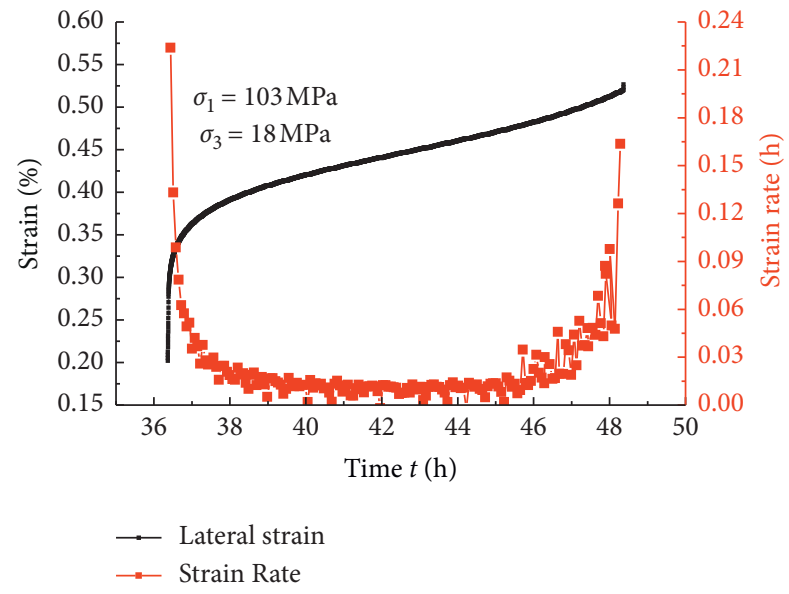

(b)

FIGURE 13: Lateral strain and creep rate of fracture confining pressure. (a) Scheme 1. (b) Scheme 2.

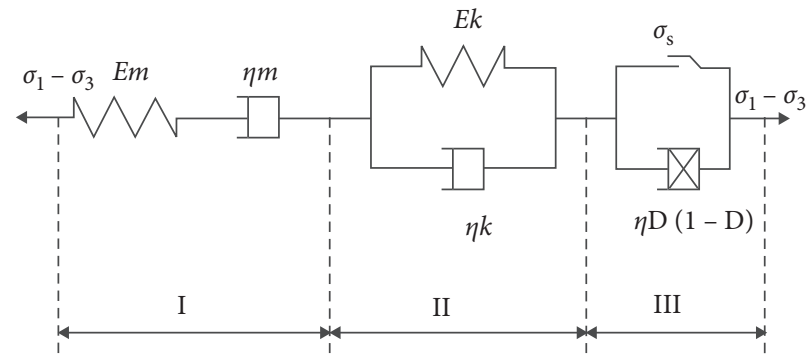

FIGURE 14: Constitutive model of nonlinear creep.

TABle 4: Parameters determined by fitting analysis based on creep tests of the gritstone rock.

\begin{tabular}{lccccccc}
\hline \multirow{2}{*}{$\sigma_{1}(\mathrm{MPa})$} & \multirow{2}{*}{$\sigma_{3}(\mathrm{MPa})$} & \multicolumn{4}{c}{ Constitutive model parameters } \\
& & $E_{m}$ & $\eta_{M}$ & $E_{k}$ & $\eta_{k}$ & $\eta_{D}$ \\
\hline 91 & 10 & $2.67 \times 10^{8}$ & $12.73 \times 10^{4}$ & 3.55 & $1.3 \times 10^{4}$ & $2.4 \times 10^{3}$ \\
103 & 18 & $1.07 \times 10^{7}$ & $4.09 \times 10^{4}$ & 1.56 & $2.7 \times 10^{4}$ & 0.03 \\
\hline
\end{tabular}

the gritstone under two unloading paths. Specific values of parameters in the creep process were obtained by solving the parameters in the model, and this model was compared with the curve obtained from the creep test. The specific values of the parameters in the creep constitutive model obtained by identification are shown in Table 4. Figures 15-17 show the Burgers fitting curve under the constant axial pressure grade unloading of the confining pressure and the fitting curve of the last grade creep curve and nonlinear creep curve under two test paths.

As known from Figures 15-17, the Burgers model can fit the decelerated creep and the stable and uniform creep but cannot match the test curve with the accelerated creep stage effectively; the nonlinear creep damage model can satisfactorily express different stages like the deceleratedstable creep stage and the decelerated-stable-accelerated creep process, which reflects the nonlinear characteristics

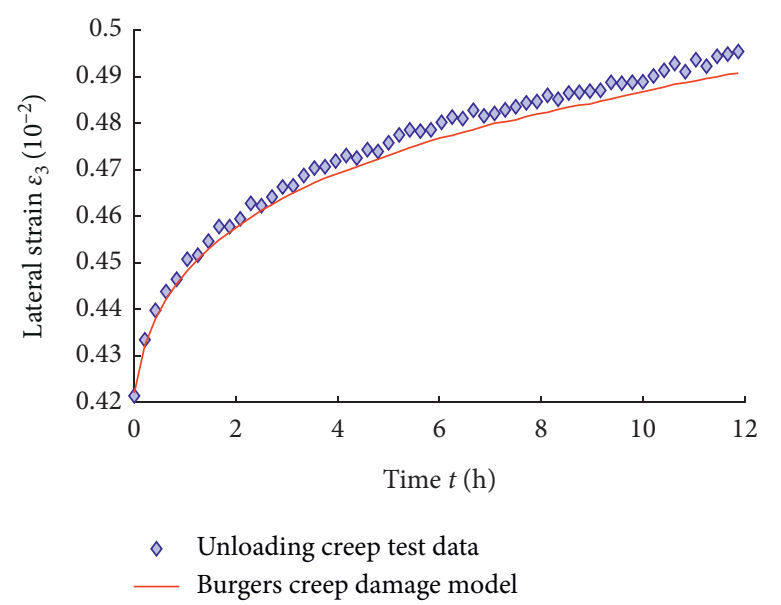

Figure 15: Burgers fitting curve of constant axial pressure unloading of confining pressure. 


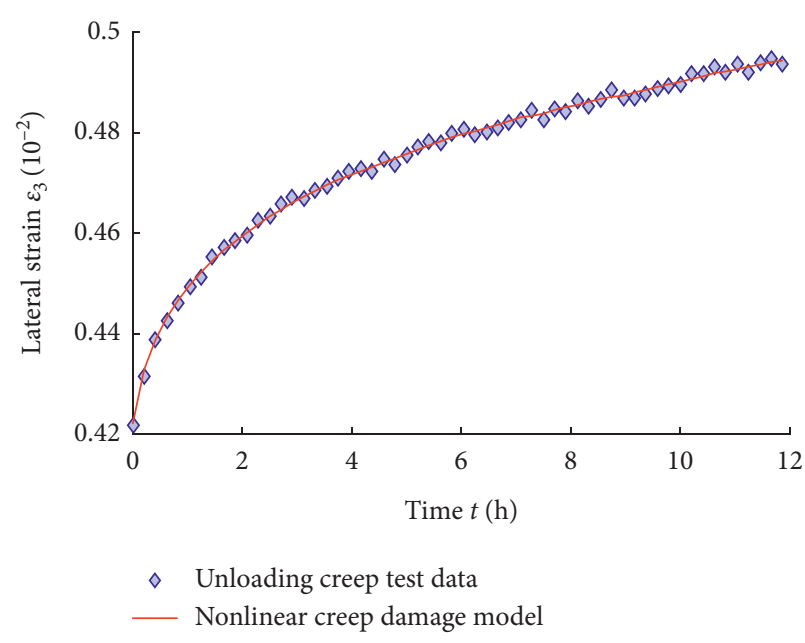

Figure 16: Fitting curve of constant axial pressure unloading of confining pressure and nonlinear creep constitutive model.

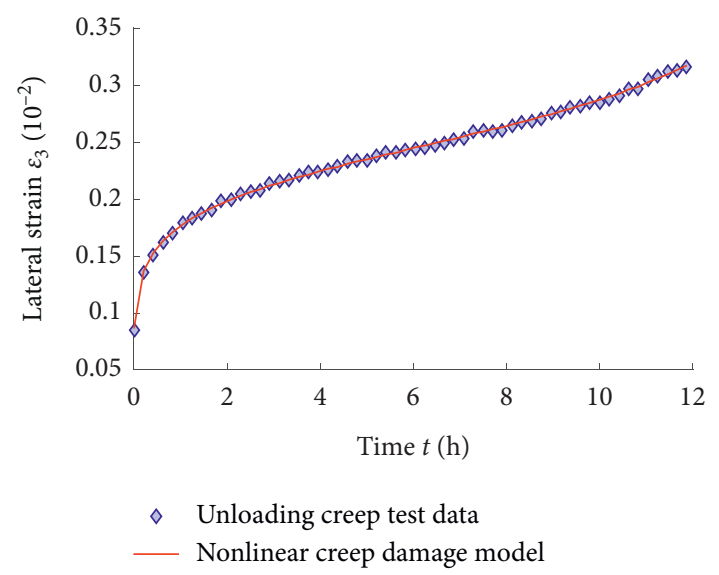

FIGURE 17: Fitting curve of constant deviatoric stress unloading of confining pressure and nonlinear creep model.

of the curves in each stage of the creep process. The fitting curve of the model was consistent with the test results, which indicates that this nonlinear creep constitutive model was suitable for this test.

\section{Conclusions}

During the creep of soft rock subjected to high stress under grade unloading conditions, the lateral creep was more significant. The creep strain and transient strain deformation decrease first and then increase; the creep deformation of the constant deviatoric stress grade unloading of the confining pressure was faster than that of constant axial pressure grade unloading of the confining pressure. The AE signal was active during unloading; the creep stage occurs after the unloading was completed, and the $\mathrm{AE}$ count decreases gradually from the active state to the subactive state. Creep was a continuous "microdynamic" process and was characterized by the obvious confining pressure effect. As shown by the failure morphology of the sample, both experience shear failure during the unloading of the confining pressure, and the failure under constant axial pressure was more serious than that under constant deviatoric stress. The main reason was that the former experiences creep for a longer duration, and the cumulative damage was greater than the latter. Through the curve fitting of the Burgers model and the nonlinear constitutive equation, the nonlinear constitutive equation can better represent the high-stress soft rock under grade unloading condition. The parameters of the nonlinear constitutive equation were inversed by the test data, and the relevant creep parameters were obtained.

\section{Data Availability}

The data used to support the findings of this study are available from the corresponding author upon request.

\section{Conflicts of Interest}

The authors declare that there are no conflicts of interest regarding the publication of this paper.

\section{Acknowledgments}

This research was supported by the National Natural Science Foundation of China (Grant nos. 51874002, 51574006, 51974009, 5174012, 52074006, 52004005, and 51674008), National Key Research and Development Plan (Grant no. 2017YFC0603003), Funds for Scientific Research Activities of Academic and Technical Leaders in Anhui Province (Grant no. 2018D187), National Natural Science Youth Fund (Grant no. 52004006), Talent Introduction Fund (Grant no. 13200013), Anhui Province Key Research and Development Plan Project (Grant no. 201904a07020010), Funding Project for Cultivating Outstanding Talents in Universities (Grant no. gxbjZD2016051), Anhui University of Science and Technology Introduction of Talents Research Fund Project, Scholastic Key Project (Grant no. QN2019113), Independent Research Fund of the State Key Laboratory of Mining Response and Disaster Prevention and Control in Deep Coal Mines (Anhui University of Science and Technology, Grant no. SKLMRDPC19ZZ012), and the Anhui Provincial Natural Science Foundation (Grant no. 2008085QE222).

\section{References}

[1] L. G. Wang and R. Q. Huang, Motion Stability Theory of Rock Mechanics System and its Application, Geological Publishing House, Beijing, China, 1998.

[2] W. W. Chen, P. B. Yuan, and X. W. Liu, "Experimental study on the creep characteristics of red-bedded soft rock under stepwise loading," Chinese Journal of Rock Mechanics and Engineering, vol. 28, pp. 3076-3081, 2009.

[3] B. S. Yang, Z. Y. Wang, Y. F. Jia, L. H. Sun, and B. Gao, "Research on control mechanism of discontinuous double shell surrounding rock of soft rock roadway in deep high stress engineering," Journal of Mining \& Safety Engineering, vol. 32, no. 5, pp. 721-727, 2015.

[4] M. J. Hu, "Research on the mechanism of time-dependent deformation of deep high-stress soft rock roadway," Ph.D. thesis, China University of Mining and Technology, Xuzhou, China, 2015. 
[5] M. C. He, H. H. Jing, and X. M. Sun, "Research progress of soft rock engineering geomechanics," Journal of Engineering Geology, vol. 8, no. 1, pp. 46-42, 2000.

[6] S. C. Hu, "Research on deformation and failure characteristics and mechanism of layered surrounding rock in deep mine roadway," Chinese Journal of Rock Mechanics and Engineering, vol. 34, no. 11, pp. 2376-2386, 2015.

[7] J. B. Zhu, B. Wang, H. P. Yang et al., "Experimental study on unloading rheological properties of shale," Chinese Journal of Rock Mechanics and Engineering, vol. 26, no. 2, pp. 45524556, 2007.

[8] H. M. Tian, W. Z. Chen, T. Tian, H. Wang, and W. S. Zhao, "Experimental and theoretical study on creep damage characteristics of soft rock," Chinese Journal of Rock Mechanics and Engineering, vol. 31, no. 3, pp. 610-617, 2012.

[9] L. Y. Zhang, Q. Y. Zhang, S. Y. Yang et al., "Triaxial rheological test and analysis of diabase unloading confining pressure in Dagangshan dam area," Journal of Central South University (Natural Science Edition), vol. 46, no. 3, pp. 1034-1042, 2015.

[10] W. Huang, K. J. Wen, D. S. Li et al., "Experiment study of lateral unloading stress path and excess pore water pressure on creep behavior of soft soil," Advances In Civil Engineering, vol. 2019, Article ID 9898031, 9 pages, 2019.

[11] C. Wang, J. Liu, L. Chen, J. Liu, and L. Wang, "Mechanical behaviour and damage evolution of Beishan granite considering the transient and time-dependent effects of excavation unloading," European Journal of Environmental and Civil Engineering, vol. 1, no. 1, pp. 1-17, 2020.

[12] D. Huang, C. Yang, R. Q. Huang, and J. Liu, "Experimental study on the effect of graded unloading on the triaxial unloading creep characteristics of marble," Chinese Journal of Rock Mechanics and Engineering, vol. 34, no. S1, pp. 28012807, 2015.

[13] Y. Wang, J. L. Wang, H. F. Deng, and R. H. Wang, "Research on rheological properties and constitutive model of soft rock under triaxial unloading," Rock and Soil Mechanics, vol. 33, no. 11, pp. 3338-3344, 2012.

[14] B. Hu, S.-Q. Yang, P. Xu, and J.-L. Cheng, "Cyclic loadingunloading creep behavior of composite layered specimens," Acta Geophysica, vol. 67, no. 2, pp. 449-464, 2019.

[15] X. Huang, Q. Liu, B. Liu, X. Liu, Y. Pan, and J. Liu, "Experimental study on the dilatancy and fracturing behavior of soft rock under unloading conditions," International Journal of Civil Engineering, vol. 15, no. 6, pp. 921-948, 2017.

[16] W. D. Yang, Q. Y. Zhang, F. Chen et al., "Triaxial test research into rheological properties of diabase in dagangshan hydropower station dam site," Journal of Sichuan University (Engineering) Science Edition, vol. 43, no. 5, pp. 64-70, 2011.

[17] H. N. Xu, X. B. Pang, J. Xu, and J. F. Liu, "Triaxial creep test of silty mudstone," Journal of Sichuan University (Engineering Science Edition), vol. 44, no. 1, pp. 69-74, 2012.

[18] X. D. Zhang and Q. Fu, "Experimental study on triaxial creep of mudstone," Journal of Applied Mechanics, vol. 29, no. 2, pp. 154-158, 2012.

[19] X. Liu, J. Yu, Y. Zhu, W. Yao, and Y. Lai, "Creep damage evolution of marble from acoustic emission and the damage threshold," Frontiers In Earth Science, vol. 8, no. 58, 2020.

[20] X. D. Zhang, X. W. Yin, and Q. Fu, "Study on the triaxial creep characteristics of purple mudstone under staged loading," Experimental Mechanics, vol. 26, no. 1, pp. 61-66, 2011.

[21] C. Gong, C. H. Li, and K. Zhao, "Short-time creep acoustic emission $b$-value characteristics of red sandstone," Journal of China Coal Society, vol. 40, no. S1, pp. 85-92, 2015.
[22] Y. Cong, Z. Wang, Y. Zheng, and L. Zhang, "Effect of unloading stress levels on macro- and microfracture mechanisms in brittle rocks," International Journal of Geomechanics, vol. 20, no. 6, Article ID 04020066, 2020.

[23] H. W. Zhou, D. Liu, G. Lei, D. J. Xue, and Y. Zhao, "The creepdamage model of salt rock based on fractional derivative," Energies, vol. 11, no. 9, 2018.

[24] M. Zhang, Q. Meng, S. Liu, D. Qian, and N. Zhang, "Impacts of cyclic loading and unloading rates on acoustic emission evolution and felicity effect of instable rock mass," Advances in Materials Science and Engineering, vol. 2018, Article ID 8365396, 16 pages, 2018.

[25] Z. J. Xu, Q. X. Qi, H. Y. Li, N. B. Zhang, and R. H. Su, "Acoustic emission characteristics of marble creep damage under different stress levels," Journal of China Coal Society, vol. 39, no. S1, pp. 70-74, 2014.

[26] C. Wu, J. F. Liu, Z. W. Zhou, and Y. Zhuo, "Study on the characteristics of triaxial creep acoustic emission of rock salt," Chinese Journal of Geotechnical Engineering, vol. 38, no. S2, pp. 318-323, 2016.

[27] D. Liu, H. W. Zhou, Y. Zhao, X. Duan, and J. Y. Ding, "Research on constitutive model of salt rock creep based on acoustic emission characteristics," Rock and Soil Mechanics, vol. 38, no. 7, pp. 1951-1958, 2017.

[28] D. Y. Jiang, Y. He, Z. H. Ouyang et al., "Uniaxial creep acoustic emission energy statistics and section morphology analysis of sandstone," Journal of China Coal Society, vol. 42, no. 6, pp. 1436-1442, 2017.

[29] Y. X. Wang, J. A. Wang, and J. Tang, "Acoustic emission characteristics of fractured rock during creep shear," Chinese Journal of Rock Mechanics and Engineering, vol. 34, no. S1, pp. 2948-2958, 2015.

[30] R. H. Wang, Y. Z. Jiang, C. Yang, and F. Huang, "A nonlinear creep damage model of layered rock under unloading condition," Mathematical Problems in Engineering, vol. 2018, Article ID 8294390, 8 pages, 2018.

[31] L. Y. Zhang, Q. Y. Zhang, S. C. Li et al., "Unloading rheological tests of hard brittle rock and its long-term strength analysis," Journal of China Coal Society, vol. 40, no. 10, pp. 2399-2407, 2015.

[32] C. Wu, F.Q. Gong, and Y. Luo, "A new quantitative method to identify the crack damage stress of rock using AE detection parameters," Bulletin of Engineering Geology and the Environment, vol. 5, pp. 1-13, 2020.

[33] X. L. Liu, Z. Zhou, X. B. Li, F. Q. Gong, and K. Du, "Experimental study on the effect of strain rate on rock acoustic emission characteristics," International Journal of Rock Mechanics and Mining Sciences, vol. 133, Article ID 104420, 2020.

[34] F.-Q. Gong and G.-F. Zhao, "Dynamic indirect tensile strength of sandstone under different loading rates," Rock Mechanics And Rock Engineering, vol. 47, no. 6, pp. 22712278, 2014.

[35] V. P. Drnevich and R. E. Gray, Acoustic Emissions in Geotechnical Engineering Practice, ASTM International, West Conshohocken, PA, USA, 1981.

[36] F.-q. Gong, S. Luo, and J.-y. Yan, "Energy storage and dissipation evolution process and characteristics of marble in three tension-type failure tests," Rock Mechanics And Rock Engineering, vol. 51, no. 11, pp. 3613-3624, 2018.

[37] Y. Zhou, H. G. Ji, Y. Z. Zhang, Z. F. Hou, and P. Xiang, "Analysis of acoustic emission characteristics of monzonitic granite during triaxial loading and unloading," Chinese Journal of Underground Space and Engineering, vol. 13, no. 2, pp. 314-321, 2017. 